\title{
Temas de América Latina y el Caribe
}

\author{
Cláudia Lorena Fonseca ${ }^{1}$ \\ Centro de Letras e Comunicação/Programa de pós-graduação em Letras, \\ Universidade Federal de Pelotas-UFPEL, Pelotas, RS, Brasil
}

\section{Apresentação}

A edição da revista Linguagem \& Ensino que ora apresentamos, intitulada Temas de América Latina y el Caribe, se constitui no fruto mais recente da prática de um trabalho de quase duas décadas integrando distintas redes acadêmicas latino-americanas buscando o compartilhar de experiências e o trabalho colaborativo entre investigadores e instituições. Seus autores, reconhecidos estudiosos em suas respectivas áreas, seja no âmbito da América Latina como além-fronteiras, são, antes de tudo, parceiros com os quais vimos compartilhando ações e projetos, além da sempre possibilidade de encontros.

Este dossiê tem como proposta, portanto, a reafirmação de vínculos e ideais, mas não apenas: ele se propõe, sobretudo, a reafirmar Latinoamerica y el Caribe, e a nossa disposição de seguirmos e resistirmos em um cenário que hoje não se apresenta favorável, se é que um dia assim se apresentou de fato, nem às liberdades; nem à investigação no âmbito das Humanidades, majoritariamente o campo de estudos dos pesquisadores aqui reunidos. 0 trabalho de compilação dos artigos que apresentamos teve início quando apenas se detectava a tensão pelo que se anunciava, inquietude pelo que estava sendo gestado, mas não sabido em suas reais proporções, em ato e resistência ao ato. Nosso objetivo passa a ser também, então, dar voz ao continente a partir da reflexão sobre temas que nos dizem respeito especificamente, visando fortalecer perspectivas de estudo que possam se desdobrar em ações, e o pensamento latino-americano.

Assim, estão reunidos, neste dossiê, dezessete artigos, provenientes de diversas instituições acadêmicas brasileiras e da América hispânica, alguns deles são trabalhos em parceria entre investigadores de distintos países, contribuições oriundas de diversas áreas, pelo que nos propomos, nesta apresentação, a apontar um nexo para a leitura, um arranjo destacando os pontos em que se tocam, ampliam ou reforçam pontos-de-vista.

Nesse sentido, começamos ressaltando a importância de um imenso projeto latino-

\footnotetext{
${ }^{1}$ Doutora em Literatura Comparada pela Universidade Federal do Rio Grande do Sul-UFRGS. Pós-doutorado na Universidad Nacional de Cuyo-UNCuyo-Mendoza, Argentina. Professora Adjunta na Universidade Federal de Pelotas-UFPel, Pelotas. Orcid: https://orcid.org/0000-0003-4787-0575

E-mail: fonseca.claudialorena@gmail.com
} 
americano: a Biblioteca Ayacucho, idealizado e concretizado por Ángel Rama, projeto editorial que busca compilar, revisar e publicar os textos clássicos das letras e o pensamento latino-americano. Um sonho de religação continental, como assim o nomeia Marcela Croce, no artigo que abre o primeiro bloco de textos deste dossiê, e que se constitui, por sua vez, também, em um pequeno dossiê, considerando-se sua unidade temática e o vínculo que mantêm entre si: são fruto das discussões que tiveram lugar na Jornada e Mostra "Biblioteca Ayacucho: un sueño de religación continental", ocorrido na Universidad de Buenos AiresUBA, em julho de 2019, organizado pela professora Croce.

Os quatro estudos desse bloco se debruçam sobre aspectos que dizem respeito à forma como se organiza a coleção, as relações que estabelece Ángel Rama com os intelectuais envolvidos no projeto, valendo-se de material de arquivo como ensaios e entrevistas, mas especialmente da correspondência do autor. Em Biblioteca Ayacucho: un sueño de religación continental, Marcela Croce se ocupa da proposta geral da coleção, além das dificuldades enfrentadas para sua concretização, tratando de reconstituir a organização da Biblioteca Ayacucho "concebida como um cânone latino-americano postulado na segunda metade do século XX, com base nos antecedentes de Andrés Bello e Pedro Henríquez Ureña". Para tanto, se debruça sobre a correspondência de Ángel Rama. Dedica-se, também, em um segundo momento, a avaliar a relação entre os textos publicados e as imagens selecionadas para a capa de cada volume buscando "demonstrar o modo como a editora foi implantada como alternativa à Utopía de América em sua dimensão de política cultural". A autora destaca a presença do Cone Sul na coleção, enfatizando a presença do Brasil efetivamente integrado na América Latina. O estudo seguinte, La Biblioteca Ayacucho según Ángel Rama: debates, definiciones y balances, de Facundo Goméz, mantém o foco, explorando o "modo como Rama concebe e põe em funcionamento a casa editorial através do exame de um material de arquivo composto por cartas, ensaios, entrevistas e escritos inéditos", demonstrando que o uruguaio construiu a Biblioteca Ayacucho visando a constituição de uma rede entre intelectuais latino-americanos exiliados e como "uma empresa de revisão coletiva da história e da identidade da região". A mesma direção, mas dedicando-se exclusivamente à correspondência do autor, segue o terceiro texto, importante aporte de Amparo Rama, filha e detentora do arquivo de Ángel Rama, em Ángel Rama en las cartas de Ia Biblioteca Ayacucho, com o qual pretende traçar um panorama da atividade do crítico uruguaio como Diretor Literário da Biblioteca Ayacucho, através das cartas a Leopoldo Zea, Caio Prado Júnior, Antonio Cornejo Polar, Idea Vilariño, Tulio Halperin Donghi, Saúl Sosnowski, Beatriz Sarlo, entre outros, e fazendo também referência a duas obras publicadas dedicadas à correspondência do autor: Un proyecto latinoamericano. Antonio Candido y Ángel Rama: correspondencia; e Diálogos latino-americanos. Correspondência entre Ángel Rama, Berta e Darcy Ribeiro. Por fim, Davidson Diniz, em La figuración brasileña en la Biblioteca Ayacucho, se dedica a discutir as relações intelectuais entre Ángel Rama e o grupo de brasileiros, que mais diretamente esteve envolvido na figuração da literatura brasileira na Biblioteca Ayacucho: Antonio Candido, Darcy Ribeiro, Berta Gleizer Ribeiro e Gilda de Mello e Souza, a partir da correspondência do autor uruguaio. Diniz busca problematizar "a 
emergência de linhas de influência entre Rama e o grupo brasileiro em contexto de trânsito ou exílios latino-americanos, priorizando nas relações intelectuais as intersecções culturais que levaram à entrada - pela primeira vez sistematizada e metodologicamente elaborada da literatura brasileira no processo de estabelecimento de um cânone latino-americanista intercontinental".

É inegável a importância do projeto idealizado e concretizado por Ángel Rama no sentido da integração latino-americana. No entanto, podemos dizer que o sonho de religar o continente, que uniu o intelectual uruguaio aos pensadores latino-americanos, é anterior ao projeto Biblioteca Ayacucho, e esse é o tema ao qual nos dedicamos em $\boldsymbol{O}$ Brasil e seus descobridores: rastros da experiência brasileira de Rubén Darío. Tratamos das viagens de Darío ao Brasil, buscando destacar o fundamental papel desempenhado pelo autor nicaraguense no sentido da integração latino-americana; e o quanto foi determinante sua ação precursora, sendo talvez o primeiro a considerar o país, colocando-o no mapa intelectual do continente, como conexão, a partir do contato direto com seus autores, levando até a Brasil o fio com o qual teceu sua rede latino-americanista, essa "confraternidad espiritual internacional", como o autor denomina.

Ainda com olhos voltados ao Brasil em suas relações com a América Hispânica, prosseguimos, agora com $O$ pensamento de Eduardo Prado e a América hispânica como exterior constitutivo do Brasil em fins do século $X I X$ e princípios do século $X X$, de Carlos Henrique Armani. Nesse estudo, o autor pretende investigar o pensamento de Eduardo Prado, e de alguns de seus interlocutores, a respeito da América Hispânica como exterior constitutivo do Brasil na virada do século XIX para o século XX, entendendo que "as disputas em torno das identidades e sua historicidade foram não somente um problema no âmbito político, como também, uma crise de valores e de sentido histórico que os autores finisseculares vivenciaram em termos de experiência histórica quando pensaram não somente o Brasil, mas um de seus principais exteriores constitutivos".

As relações entre literatura e história, são abordadas por Claudio Maíz em Nuevas percepciones de la historicidad en la novelística contemporánea de América Latina, no qual o autor se ocupa "de uma abordagem em torno à produtividade da historicidade em outros moldes genéricos latino-americanos recentes". Nesse sentido, empreende uma breve revisão estado da questão que diz respeito à consciência histórica recente e algumas de suas narrativas, além de revisar algumas categorias da narratividade, tais como o tempo, a personagem e a memória, no intuito de alcançar seu objetivo. De acordo com Maíz, novas percepções do passado têm surgido, as quais, a seu modo de ver, são formalizadas de maneira radicalmente diferente, a tal ponto que permitem que se dê por fechado o ciclo da chamada Nueva Novela Histórica, motivo pelo qual, acreditamos, constitui-se em um importante aporte, promovendo uma atualização das discussões que se fazem em torno a essa noção. Ainda no terreno do literário, Andrés Oscar Lora Bombino e Roberto Garcés González, em Alejo Carpentier: La expresión de lo real maravilloso americano, a setenta años de una teoría, buscam destacar a relevância da obra do autor cubano, bem como de 
sua teoria do real maravilhoso americano, como essencial contribuição à cultura de Nuestra América. Para Lora e Garcés, a obra de Carpentier propicia um rico testemunho do processo cultural cubano, latino-americano e universal, dado que a totalidade da criação carpenteriana está constituida em função do processo cultural do mundo e o papel que pode jogar na transformação do homem.

Resistência é a palavra e literatura o suporte em $\boldsymbol{A}$ resistência de um bibliotecário morto retido em uma universidade: Alegres memórias de um cadáver, de Roberto Gomes, de Cleiry Carvalho, no qual a autora se dedica a refletir sobre o que significou politicamente para a educação o período da Ditadura militar no Brasil no âmbito universitário. Segundo Carvalho, o romance de Roberto Gomes "oferece ao leitor o ensejo de transpor a sátira fantasiosa dos espaços acadêmicos para uma crítica muito mais profunda da dinâmica social mais ampla das práticas costumeiras dentro e em torno da universidade". Espaços coletivos no período dos anos de chumbo na América Latina é também o tema do estudo de Ramiro Zó, El Chile intramuros de las narrativas de encierro. Nele, o autor procede à análise da visão do Chile intramuros em quatro narrativas de confinamento: Tejas verdes. Diario de un campo de concentración en Chile de Hernán Valdés (1974), Cerco de púas. Un candente testimonio de represión de Aníbal Quijada Cerda (1977), Dawson Isla 10 de Sergio Bitar (1987) y Frazadas del estadio de Jorge Montealegre I (2003). De acordo com Zó, "a gênese escritural de certos relatos testemunhais latino-americanos está condicionada pela violência carcerária do confinamento dos próprios autores, muitas vezes militantes e intelectuais comprometidos com causas liberacionistas em tempos ditatoriais". Esta escrita é concebida "desde, sobre e em torno ao cárcere, e essa condição de confinamento permeia consideravelmente a gênese desses textos". Ainda segundo o autor, nesta gênese escritural a visão do cárcere, o espaço subjetivo da testemunha-vítima-autor adquire imenso e essencial significado para a leitura destes textos. Em diálogo com os dois estudos anteriores está Fijar la memoria visual, de Luis Carlos Toro Tamayo, no qual o autor busca explicar a relação entre memória e fotografia e o quanto essa relação pode aportar ao esclarecimento da verdade, à justiça e à reparação por parte do Estado. As imagens ocupam grande parte das nossas vidas e buscamos fixar esses instantes em algum suporte, o que vai forjar, com o tempo, nossos arquivos de recuerdos. O que interessa ao autor, especificamente, é a forma como guardamos esses recuerdos, pois esta irá dizer "da importância desse momento que ficou cristalizado no tempo e que hoje passa a ser nossa memória pessoal".

$\mathrm{Na}$ sequência, dois estudos vinculados mais estreitamente às Ciências Sociais. No primeiro deles, Configuración socio histórica de un actor social colectivo. Reflexiones y propuesta teórica en clave interdisciplinar, de Celia Cristina Basconzuelo, a autora busca refletir sobre a categoria de ator social coletivo (ASC). Basconzuelo entende que o conceito ASC define um sujeito histórico cuja construção coletiva "provém de uma trajetória em que se estabelece uma experiência de ação comum, localizada e de visibilidade pública, onde é desenvolvida certa identificação que o posiciona em relação a um entorno sócio-histórico e sobre o qual pode chegar a incidir". Nesse sentido, sua investigação propõe algumas 
dimensões de análise para o estudo da configuração sócio-histórica desse sujeito, a partir de ferramentas conceituais interdisciplinares, em especial aquelas fornecidas pela história, pela teoría social e pela geografia; já no segundo estudo, de Adela Bork, Las ciencias sociales en sus construcciones y controversias: Proximidades y vínculos con y desde lo social, a autora propõe, a partir de uma perspectiva sócio-histórica, uma reflexão sobre a construção disciplinar das ciências sociais contemporâneas, buscando que se possam identificar "aqueles movimentos que incidem diretamente nas formas de explicar o social não como um todo homogêneo, mas sim como formas sociais que se constroem orgânica e inorganicamente", o que possibilita analisar e pretender que os processos culturais que se orientam para o "questionamento e a promoção de mentalidades podem ser explicados em chaves complexas e/ou em uma espécie de continuum canônico que ratifica a distância acima mencionada entre sociedade e ciência". Para Bork, interrogar o estado da questão relativa às ciências sociais e aos câmbios culturais, segue como um desafio significativo "se a pergunta se configura questionando as dis-continuidades e influência que tem o discurso e prática científica no interior de uma determinada sociedade".

Alfabetización académica de los estudiantes de Geología y Paleontología de una universidad pública argentina, de María Angélica Diez; David Alberto Londoño-Vásquez e Norma Cech, inaugura o último bloco de artigos. Nele, seus autores, considerando que os "diferentes níveis de alfabetização acadêmica inicial dos estudantes universitários têm uma relação direta com o desempenho em seus primeiros anos de formação acadêmica, investigam esses níveis nos estudantes que ingressaram nas Licenciaturas em Geologia e em Paleontologia em 2018 e 2019 em uma universidade argentina". Seguindo-se a esse estudo, nos encontramos com o aporte de Margoth Mena-Young, La narrativa pública en salud: análisis de grandes reportajes sobre el ébola. Mena-Young é investigadora na área da Comunicação e, nesse trabalho, se dedica a uma análise das narrativas de grandes reportagens publicadas sobre a epidemia de ebola em três países ibero-americanos, as quais foram coletadas no primeiro semestre de 2015, ao final do primeiro ano do surto da doença na África, nos diários El País, da España; El Universal, do México e La Nación, da Costa Rica. A autora analisa as estratégias narrativas dos textos a partir de uma abordagem qualitativa de suas estruturas e recursos literários.

As questões relativas à saúde, mas abordadas a partir dos pressupostos de área distinta a do estudo anterior, são o tema do estudo de Elizabeth Martínez Buenabad e Michele Neves Meneses, Educación y salud intercultural. Reflexiones y miradas compartidas entre México y Brasil, a partir do qual as autoras pretendem promover um profundo e analítico diálogo que recupere como eixo central o tema do intercultural para dois campos básicos em toda sociedade: educação e saúde. Nesse sentido, se aplicam a um debate em torno a temas como "políticas públicas promovidas pelos Estados nacionais; e do papel desempenhado pelas instituições e organizações responsáveis pela regulamentação do tema do ensino superior e saúde (OMS, UNESCO, OPS)", ao mesmo tempo em que fazem referência a experiências e metodologias autônomas, desenvolvidas no México e no Brasil, 
que visam gerar práticas e modelos alternativos que dão conta das especificidades culturais de determinado grupo social. Por fim, fechamos nosso dossiê com a contribuição de Francisco Luis Giraldo Gutiérrez; Luis Felipe Ortiz Clavijo e Samir Zuñiga-Miranda, os quais se debruçam sobre o importante e atual tema da produção de novos conhecimentos, em Políticas de Ciencia, Tecnología e Innovación en América Latina y el Caribe y su influencia en la producción y apropiación de la CTI, no qual analisam a influência das políticas de CTI na produção e apropriação da CTI. Afirmam os autores que a nível de América Latina e Caribe as políticas que regem e administram a ciência e a tecnologia constroem suas agendas. No entanto, se evidencia "una ausencia importante en los propósitos de implementación, en tanto los elementos conceptuales de la apropiación no son considerados". E são as particularidades dessa relação que lhes interessa investigar.

Todos os artigos selecionados para este dossiê abordam temas que dizem respeito a aspectos da nossa realidade e se destacam por sua diversidade e pela relevância de seus temas. Estimulam o debate e propiciam a manutenção de espaços de discussão intelectual. Agradecemos aos autores e às autoras, do Brasil, da Argentina, do Chile, da Colômbia, México, Costa Rica e Cuba que contribuíram com suas reflexões, por sua confiança.

Uma excelente experiência a todos. Boa leitura. 